of the kiln, render fish-smoking an art which is difficult to practise. In 1939 a mechanical kiln was developed at Torry which simplified the process and made it much easier to control. Although the industry was at first slow to adopt the new kilns, an increasing number of firms are now doing so. Intriguing possibilities are, however, now being suggested as a result of basic physical and chemical work on the composition of wood smoke. It has been shown that virtually all the smoke constituents on smoked fish are derived from the invisible vapour phase and not the visible particulate phase. The practicability of smoking fish with 'smokeless' smoke and further developments as well are envisaged.

There is a continuous programme of work at Torry on the improvement of the efficiency of conventional fish-meal plant. Emphasis is put upon methods of increasing production, plant efficiency and nutritive value of the product.

It is important to stress that the high standing of the Torry Research Station within the fish industry itself is very largely due to the considerable amount of consultation and discussion which takes place with the industry and, not less important, the very good relationship built up between individual scientists and various people 'in the trade'. Much of the development and survey work carried out within the past ten years would have been quite impossible without the close and friendly co-operation of the industry; on this personal contact between govern ment research workers and the industry the future development of this relatively undeveloped and traditional industry, without any research organization of its own, depends. G. H. O. Buratess

\title{
FISHERY RESEARCH
}

$\mathrm{D}$ R. BREDER has prepared a valuable review of work on social grouping in fish*; it also contains new data, though it is sometimes a little difficult to pick these out. He discusses in detail the various types of groups: the aggregation, where the individuals are not 'polarized'; the school, where they are; and the pod, where the fish are in physical contact. These types of groups are illustrated by outstandingly good photographs, those of pods and fish in 'orderly files' being the most interesting.

Descriptions of new work are mainly of the effect of light intensity and colour on a number of species and the analysis of the internal structure of schools. In the experiments on the effect of the wave-length of light the fish were given a choice between different colours, the intensity of the different colours being equated photometrically. No attempt was made, by determining the spectral sensitivity of the fish, to equate the subjective intensity, or intensity as it appeared to the fish. Of particular interest are Dr. Breder's discussions on the leadership of schools, the school as a super-organism and the evolution of schooling behaviour. There is also a section on schooling in terms of cybernetics, where the point is made that the survival of a species which has grouping tendencies should perhaps be considered from the

* Bulletin of the American Museum of Natural History. Vol. 117, Article $6:$ Studies on Social Groupings in Fishes. By C. M. Breder Jr. Pp. 393-482 + plates 70-80. (New York: American Museum of Natural History, 1959.) 1.50 dollars. point of view of how they have got over the danger involved, rather than that such tendencies automatically have survival value.

Dr. Loukashkin's and Dr. Grant's work on Sardinops caerulea*, a species of great commercial importance, has much in common with Dr. Breder's but is more limited in extent. It is again well illustrated with photographs. Like other clupeoids, Sardinops is not an easy subject for experiment, but results have been obtained which show the importance of light for the maintenance of school formation and that fright reactions are elicited by red lights and by flashing white lights. When given the choice between red, green, blue and white light, the fish avoided red and preferred blue and green to white. As in Dr. Breder's work, this technique has a limitation in that the intensities of the different colours were not equated subjectively but only photometrically.

This type of behaviour work, which may be considered important as an aspect of fisheries research, is now being produced in much greater quantity than before the War, and it is particularly welcome to the fisheries research worker when it is concerned with species of commercial importance.

\section{J. H. S. BLAXTER}

* Proceedings of the California Academy of Sciences. Vol. 29 No. 15: Behavior and Reactions of the Pacific Sardine Sardinop caerulea (Girard) Under the Influence of White and Colored Laratiops Darkness. By A.S. Loukashkin and N. Grant Pp. 509-548 Francisco: California Academy of Sciences, 1959.)

\section{THE ONTARIO RESEARCH FOUNDATION}

$\mathrm{T}$ HE annual report of the Ontario Research Foundation for 1958 (pp. 36. Toronto : Ontario Research Foundation, 1959) includes, besides the report of the director, Dr. H. B. Speakman, a summary of the work of the various sections, a list of papers published during the year, the financial statement and details of the Board of Governors and professional and technical staff. There is also a list of grants for postgraduate studies in science for the period 1958-59, for which grants in 1958 totalled 145,204 dollars. In biochemistry three major projects, dealing with the development of an all-temperature biscuit spread for the Defence Research Medical
Laboratories, tea, and the recovery of pure individual amino-acids from wheat gluten after hydrolysis, were completed, and two major studies are in progress under the Rice Mills Fellowship. In chemistry, activity was maintained at a high level. The three-year survey of air pollution of the Hamilton area was completed, while the development of gas chromatography procoeds apace. In a study of factors controlling the crystallinity of polymers, techniques developed for preparing polymers of butane with 50 per cent of crystallinity are being used to study the relation between the type of catalyst and polymer structure. A novel ion-exchange process for recovering ammonia. 